Clinical, radiological, and histological data on the patients may be obtained from a table deposited with the Librarian, Royal Society of Medicine, Wimpole Street, London W1.

Requests for reprints should be addressed to Dr M Reiner.

\section{References}

${ }^{1}$ Anderson, J, et al, Lancet, 1954, 2, 720.

${ }^{2}$ Henneman, P H, et al, fournal of Clinical Investigation, 1956, 35, 1229.

${ }^{3}$ McSwiney, R R, and Mills, I H, Lancet, 1956, 2, 862

4 Mather, G, British Medical fournal, 1957, 1, 248.

5 Scholz, D A, Fournal of the American Medical Association, 1959, 169, 682.

6 Jackson, W P U, and Dancaster, C, fournal of Clinical Endocrinology, 1959, $19,658$.

7 Parfitt, A M, et al, Clinical Science, 1964, 27, 463.

${ }^{8}$ Bell, N H, and Bartter, F C, Annals of Internal Medicine, 1964, 61, 702.

9 Bell, N H, and Bartter, F C, Acta Endocrinologica, 1967, 54, 173.

10 Goldstein, R A, et al, American fournal of Medicine, 1971, 51, 21.

11 Hunt, B J, and Yendt, E R, Annals of Internal Medicine, 1963, 59, 554

12 Hendrix, J Z, Annals of Internal Medicine, 1966, 64, 797.

13 Miller, B, et al, in Proceedings of the Vth International Conference on Sarcoidosis, Prague, p 319. Praha, Universita Karlova, 1969.

14 North, K, et al, Medical uses of $\mathrm{Ca}^{47}$, Technical Report Series No 10. Vienna, International Atomic Energy Agency, 1962.

15 Fraser, R, et al, Quarterly Fournal of Medicine, 1960, 29, 85.

16 Reiner, M, et al, Calcified Tissue Research, 1970, 4, 95.

17 Bronner, F, Nutritio et Dieta, 1962, 3, 22.

18 Heaney, R P, and Skillman, T G, fournal of Laboratory and Clinical Medicine, 1964, 64, 29.

19 Melvin, K E W, et al, Quarterly fournal of Medicine, 1970, 39, 83.

${ }^{20}$ McCance, R A, and Widdowson, E M, The Composition of Foods. London, HMSO, 1960.
21 Reifenstein, E C, et al, fournal of Clinical Endocrinology, 1945, 5, 367.

22 Wootton, I D P, Microanalysis in Medical Biochemistry, 4th edn, London Churchill, 1964.

${ }^{23}$ Nordin, B E C, and Fraser, R, Lancet, 1960, 2, 947.

24 Winnacker, J L, et al, New England fournal of Medicine, 1968, 278, 427.

${ }^{25}$ Harrell, G T, and Fisher, S, fournal of Clinical Investigation, 1939, 18, 687.

${ }^{26}$ Davidson, C N, et al, Radiology, 1954, 62, 203.

27 Holt, J F, and Owens, W I, Radiology, 1949, 53, 11.

${ }^{28}$ Longcope, W T, and Freiman, D G, Medicine, 1952, 31, 1.

${ }^{29}$ Gendel, B R, et al, American fournal of Medicine, 1952, 12, 205.

30 Cushard, W G, jun, et al, New England fournal of Medicine, 1972, 286, 395.

31 Lebacq, E, et al, Postgraduate Medical fournal, 1970, 46, 526.

32 James, D G, Acta Medica Scandinavica, 1964, 176, Suppl No 425, p 203.

${ }^{33}$ Basset, G, Bulletins et Mémoires de la Société Médicale des Hôpitaux de Paris, 1964, 115, 583.

34 Turiaf, J, and Battesti, J P, Revue de la Tuberculose et de Pneumologie, $1971,35,569$.

${ }^{35}$ Scadding, J G, British Medical fournal, 1950, 1, 745.

36 Taylor, R L, et al, American fournal of Medicine, 1963, 34, 221.

37 Dent, C E, Postgraduate Medical fournal, 1970, 46, 471.

${ }^{38}$ Mawer, E B, et al, Nature, New Biology, 1971, 232, 188

${ }^{39}$ Thomas, W C, jun, fournal of Clinical Investigation, 1959, 38, 1078.

${ }^{40}$ Bell, N H, et al, American fournal of Medicine, 1964, 36, 500.

${ }^{41}$ Dent, C E, and Watson, L, British Medical fournal, 1966, 1, 646.

42 Pedersen, K O, Acta Medica Scandinavica, 1967, 182, 781.

43 Winnacker, J L, et al, American Fournal of Medicine, 1969, 46, 305.

${ }^{44}$ Bohnen, R F, et al, fournal of the American Medical Association, 1971, 217, 1385.

45 Reiner, M, et al, Proceedings of the Ninth European Symposium on Calcified Tissues, p 91. Vienna, Facta-Publication, 1973.

46 Massare, D, et al, American Review of Respiratory Disease, 1966, 93, 929.

47 Van Creveld, S, Annales de Pediatrie, 1941, 157, 1.

${ }^{48}$ Klatskin, G, and Gordon, M, American fournal of Medicine, 1953, 15, 484.

\title{
Mild hypertension: a clinical trial conducted in hospital and general practice
}

\author{
H E JOESBURY, \\ C A PHILLIPS, \\ R T GARRETT, \\ E WILKES, A J SMITH
}

British Medical fournal, 1976, 2, 1476-1479

\begin{abstract}
Summary
To compare findings in a hospital trial of hypotensive drugs with those in a general practice trial several patients with mild hypertension were studied at the same time in hospital and in general practice. They received bendrofluazide and potassium chloride or bendrofluazide, potassium chloride, and reserpine according to a double-blind crossover protocol, and blood biochemical values were studied over eight weeks and six months. When reserpine was withdrawn from nine women they followed a modified protocol comparing bendrofluazide and potassium chloride with potassium chloride alone.
\end{abstract}

Department of Community Care and General Practice, University of Sheffield, Sheffield

H E JOESBURY, MB, MRCGP, general practitioner research assistant

E. WILKES, FRCP, FRCGP, professor

Glaxo Laboratories Ltd, Greenford, Middlesex

R T GARRETT, MPs, clinical trials associate

Department of Pharmacology and Therapeutics, University of Sheffield, Sheffield S6 3DA

C A PHILLIPS, BSC, research technician

A J SMITH, DM, FRCP, consultant physician and associate in medicine
The blood pressure values measured by the general practitioners were similar to those measured in hospital. Both the diuretic alone and the diuretic with reserpine produced significant falls in blood pressures. Although plasma renin activity increased on diuretic treatment, continued treatment did not produce a further increase, and levels gradually declined towards normal.

\section{Introduction}

Clinical trials of antihypertensive drugs are usually carried out in hospitals, where strict control of conditions can be ensured. Difficulty in recruiting enough patients in hospital and a feeling that less artificiality attaches to studies conducted away from the wards or outpatient clinics have led recently to many more trials being performed exclusively in general practice. ${ }^{12}$ So far as we know no comparison has ever been made of results obtained in the same patient population studied at the same time both in general practice and the hospital clinic. This doubleblind crossover study was designed to provide such a comparison using well-established treatment for mild hypertension.

In most clinical trials short-term changes in the patients' blood chemistry are reported, from which long-term conclusions are sometimes drawn. As a secondary objective in this study we have examined and compared the changes in chemical values in the plasma (including plasma renin activity (PRA)) over both short (eight weeks) and longer periods (six months) of treatment. 


\section{Patients and methods}

Forty-eight newly-diagnosed mildly hypertensive patients were referred from 36 general practitioners representing 17 practices in and around Sheffield. After initial investigation 19 women (aged 35-70, mean 51 years) and 14 men (aged 38-66, mean 49 years) were considered suitable for the trial. They each had a diastolic blood pressure of 100-115 mm Hg recorded on more than one occasion and were free from gout, diabetes, renal and endocrine disease, and active peptic ulceration and had no history of depressive illness. Patients were allocated randomly to two treatment groups to receive daily either $5 \mathrm{mg}$ bendrofluazide with $1260 \mathrm{mg}$ potassium chloride in a gradual release wax matrix base ( 2 tablets of Neo- NaClex-K) or the same formulation with $0.25 \mathrm{mg}$ reserpine included. After eight weeks' treatment they followed the alternative schedule for a further eight weeks. Each treatment period was preceded by a four-week placebo or "washout" period, when the patient took only $1260 \mathrm{mg}$ potassium chloride daily. At all stages of the trial the patient took two tablets, identical in appearance, as a single morning dose. They were dispensed in coded bottles by the hospital pharmacist.

Blood pressure was measured with a mercury sphygmomanometer at each of three initial hospital visits, and in the same way alternately in hospital and general practice every two weeks for the 24-week trial. Lying pressures were measured first after two to three minutes of recumbency. Standing pressures were taken immediately afterwards. We could not provide more objective blood pressure measurements as so many general practitioners took part in the study. At the hospital the pressures were measured, with very few exceptions, by HEJ.

Initial investigations included 12-lead electrocardiography, chest radiography, analysis of mid-stream urine specimen, and measurement of 24-hour urinary catecholamine excretion. Fasting blood urea, electrolytes, urate, glucose, cholesterol, triglycerides, calcium, full blood count, and erythrocyte sedimentation rate were measured in venous blood taken during the initial screening of the patients and again at the 12th and 24th weeks of the study. Plasma renin activity (PRA) was measured in venous blood withdrawn between 9.30 and 10 am after the fasting patient had been lying down for at least an hour. Samples were assayed by normal laboratory techniques and PRA was measured by a modification of the radioimmunoassay method of Cohen et al:3

When the initial 24 weeks of the trial were over the code was broken and each patient received the treatment giving the more satisfactory control. Monthly visits to the general practitioner were made before the patient returned to hospital one year from the start of the trial.

When the safety of reserpine came into question ${ }^{4-6}$ during the trial the protocol was modified so that women no longer received this compound. The modification gave rise to a subgroup of nine patients in whom bendrofluazide with potassium chloride was compared with potassium chloride alone.

\section{Results}

Of the 33 patients admitted to the trial 24 (10 women and 14 men) followed the original protocol and nine (all women) followed the modified protocol excluding reserpine. Twenty-six patients completed the first six months of the trial (19 on original protocol; 7 on modified protocol). One patient was withdrawn because the diastolic blood pressure rose above $120 \mathrm{~mm} \mathrm{Hg}$ soon after the beginning of treatment. One patient moved away and two others failed to attend for follow-up. Three patients were withdrawn because of unwanted side effects. The total number of attendances required of each patient during the first 24 weeks of the study was 17, 10 of them at hospital. Of those following the original protocol, only 12 patients attended on every occasion, but $16 \mathrm{kept}$ all their hospital appointments. Complete recordings were obtained for six patients who were following the modified protocol.

\section{BLOOD PRESSURE RESPONSES}

Short term-The results are those of the 12 patients who attended every appointment in the first 24 weeks. Hospital data showed that mean systolic and diastolic blood pressures fell significantly from control values (obtained before the trial started) with a 5-mg dose of bendrofluazide, and a further significant reduction was obtained in mean standing diastolic (but not systolic) pressures with the addition of reserpine. No significant differences in mean systolic or diastolic blood pressures (lying or standing) were found between control and either of the two potassium chloride (placebo) periods. Results obtained in general practice allowed identical conclusions to be drawn about the efficacy of treatment, with the exception that the mean lying systolic pressures were not significantly different from control values after bendrofluazide and potassium chloride alone. Nevertheless, the standard deviations for mean pressures measured in general practice were generally wider than those derived from the hospital data (fig 1).

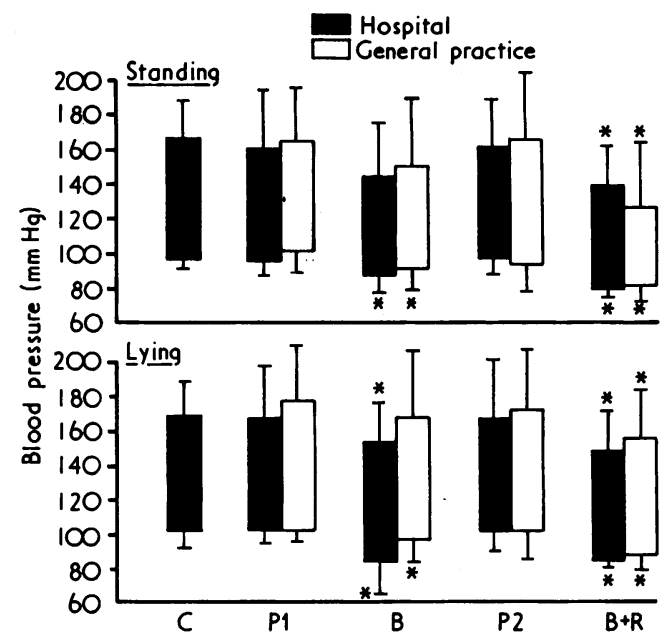

FIG $1-$ Mean ( \pm SD) systolic and diastolic blood pressures measured in hospital and in general practice, standing and lying, in 12 patients with mild hypertension. $\mathrm{C}=\mathrm{Control}$ data in run-in period. $\mathrm{P} 1, \mathrm{P} 2=$ Placebo periods (potassium chloride only). $\mathrm{B}=$ Bendrofluazide and potassium chloride. $B+R=-$ Bendrofluazide, potassium chloride, and reserpine. *Significantly different from control and placebo values $(\mathrm{P}<0.05$; paired $t$ test).

The data from hospital and general practice were compared and showed no significant differences at any part of the study, apart from the recumbent systolic pressures during the first placebo period and the period on bendrofluazide and potassium chloride. Results obtained in the six women patients who completed the modified protocol using diuretic and potassium chloride showed only a nonsignificant downward trend of blood pressure when the diuretic was taken. Patient numbers were probably too small to expect to find significant differences.

Changes in mean fasting plasma potassium, blood urea, and urate $( \pm S D)$ occurring during short-or longer-term treatment of hypertension with bendrofluazide and potassium chloride, with $(B+R)$ or without $(B)$ reserpine.

\begin{tabular}{|c|c|c|c|c|c|c|c|c|c|c|c|}
\hline & & & & \multicolumn{4}{|c|}{ Short term ( 8 weeks) } & \multicolumn{4}{|c|}{ Long term (6 months) } \\
\hline & & & & \multicolumn{2}{|c|}{$n=23$} & \multicolumn{2}{|c|}{$n=16$} & \multicolumn{2}{|c|}{$n=18$} & \multicolumn{2}{|c|}{$n=5$} \\
\hline & & & & Control & B & Control & $\mathbf{B}+\mathbf{R}$ & Control & B & Control & $\mathbf{B}+\mathbf{R}$ \\
\hline $\begin{array}{l}\text { Plasma potassium } \\
\text { Blood urea ... } \\
\text { Blood urate ... }\end{array}$ & $\because$ & $\begin{array}{l}\ldots \\
\cdots\end{array}$ & $\begin{array}{l}. \\
\therefore\end{array}$ & $\begin{array}{l}4 \cdot 26 \pm 0.36 \\
5 \cdot 17 \pm 1 \cdot 28 \\
0 \cdot 34 \pm 0.08\end{array}$ & $\begin{array}{l}3.85^{*} \pm 0.45 \\
5.79^{*} \pm 1.16 \\
0.39^{*} \pm 0.12\end{array}$ & $\begin{array}{l}4 \cdot 31 \pm 0.4 \\
5 \cdot 25 \pm 1 \cdot 3 \\
0 \cdot 39 \pm 0.06\end{array}$ & $\begin{array}{l}4.0^{*} \pm 0.57 \\
6.02^{*} \pm 1.21 \\
0.43^{*} \pm 0.07\end{array}$ & $\begin{array}{l}4 \cdot 16 \pm 0.36 \\
5 \cdot 12 \pm 1.29 \\
0 \cdot 31 \pm 0.06\end{array}$ & $\begin{array}{l}3.71 * \pm 0.36 \\
6.02^{*} \pm 1.29 \\
0.34^{*} \pm 0.08\end{array}$ & $\begin{array}{l}4.44 \pm 0.34 \\
5.54 \pm 1.49 \\
0.43 \pm 0.07\end{array}$ & $\begin{array}{l}4 \cdot 2 \pm 0 \cdot 16 \\
6 \cdot 07 \pm 1.44 \\
0.48 \pm 0.05\end{array}$ \\
\hline
\end{tabular}

*Significantly different $(\mathrm{p}<0.05)$ from control value on paired $t$ test. 
Long-term-Eighteen patients continued to take bendrofluazide and potassium from weeks 24 to 52 of the trial, including 9 women in whom reserpine had to be avoided. Mean blood pressures remained significantly lower than control values after one year's treatment but were not significantly different from those measured at 24 weeks. The same conclusion was drawn from the results in six patients who received reserpine and the diuretic from weeks 24 to 52 .

\section{BIOCHEMISTRY}

No significant changes in fasting blood cholesterol, calcium, or glucose concentrations were found after treatment with bendrofluazide with or without reserpine, either in the short term ( 8 weeks) or after six months' continuous treatment.

Both the mean fasting blood urea and urate concentrations, although remaining within the normal range, were significantly higher in the short-term ( 8 weeks) period on bendrofluazide regardless of the presence of reserpine. Over the next six months they remained significantly raised only in those patients receiving the diuretic and potassium chloride tablet alone (see table).

The mean plasma potassium concentration remained within normal limits at all stages of the study although there was a significant lowering with both treatments in the short term. In the long term the plasma potassium concentration returned to pretreatment levels in the five patients who received reserpine as well as the diuretic (see table).

\section{PLASMA RENIN ACTIVITY}

The mean PRA levels at the beginning of the trial fell within the normal range for the laboratory in all patients.

PRA (not corrected for 24-hour sodium excretion ${ }^{7}$ ) rose significantly in those patients who received bendrofluazide for eight weeks, but returned to pretreatment levels after treatment had been continued for a further six months. Among the patients who received reserpine plus bendrofluazide no significant increase in the mean PRA could be shown either in the short or long term. The control values in this group were not significantly different from those of the larger group who did not receive reserpine (fig 2 ).

\section{Discussion}

The results obtained in the random allocation, double-blind, balanced crossover study in mild hypertension were not sig-

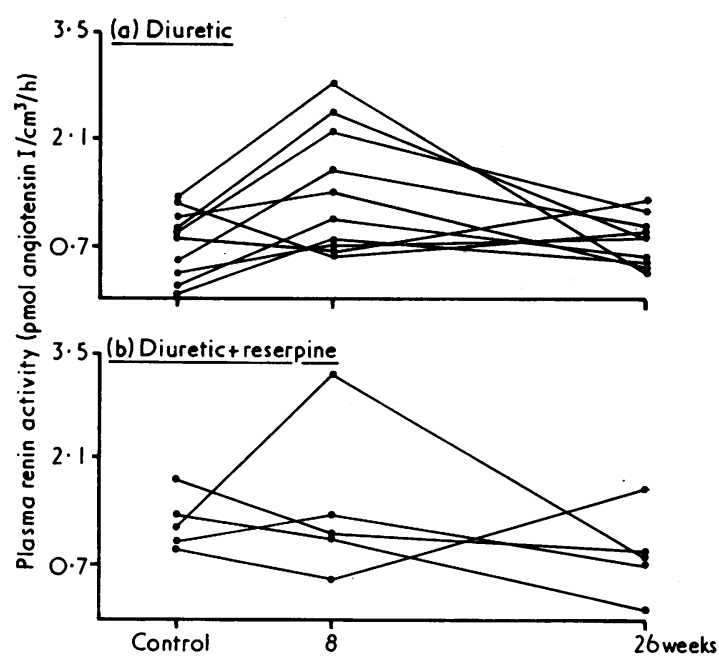

FIG 2-Response of plasma renin activity to treatment with (a) bendrofluazide and potassium chloride over eight and 26 weeks in 10 patients and $(b)$ bendrofluazide, potassium chloride, and reserpine over the same periods in five patients. Mean eight-week response with diuretic and potassium chloride was significantly different from both control and 26-week mean $(\mathrm{P}<0.05$; paired $t$ test).

Conversion: SI to traditional units-PRA: $1 \mathrm{pmol}$ angiotensin $\mathrm{I} / \mathrm{cm}^{3} / \mathrm{h} \approx 1.429 \mathrm{ng}$ angiotensin $\mathrm{I} / \mathrm{cm}^{3} / \mathrm{h}$. nificantly different whether observations were made in the hospital clinic or the general practitioner's surgery. Had this study been carried out exclusively in general practice the conclusions drawn would have been identical to those obtained in hospital despite the obvious and expected greater scatter of blood pressure measurements made by the many observers in general practice.

Our patients had only modest increases in blood pressure, and the pressure falls observed with treatment were not large. Nevertheless, mean pressure fell significantly both with a diuretic alone and with a diuretic and reserpine.

The increase in blood urea and urate concentrations with diuretic treatment is well known, and it has been suggested ${ }^{*} 9$ that the short-term increase in PRA caused by diuretics can be counterbalanced by the simultaneous administration of drugs such as beta-blockers or reserpine, which tend to reduce renin secretion. The secondary effect of a rise of PRA may be stimulation of endogenous aldosterone secretion and a tendency towards hypokalaemia. Patients who received reserpine with the diuretic had a smaller, but still significant, fall in plasma potassium concentration than those who received diuretics alone.

Of greater theoretical interest is the observation (fig 2) that although short-term diuretic treatment was associated with an increase in PRA, the continued use of bendrofluazide and potassium chloride alone did not produce further increases in PRA. Indeed, the PRA concentrations of our patients reverted towards normal after the longer period of continuous diuretic treatment. Long-term compliance with the treatment schedules was not assessed by formal tablet counts, but all patients for whom long-term conclusions were drawn had perfect attendance records and showed a persistent pharmacological response that was significantly different from their control data.

There are contradictory views on the effects of long-term diuretic treatment on PRA. Tarazi et al ${ }^{10}$ showed a consistent fall in PRA in eight patients treated with diuretics for six to 24 months after treatment was discontinued. On the other hand, Bourgoignie et $a l^{11}$ showed a mean increase in PRA after three weeks' treatment with diuretics but normal PRA in patients with no dietary sodium restriction who had been receiving diuretics for over two months. Many of the other reports on this topic are confused by lack of standardisation of procedures for obtaining blood for PRA, in the laboratory determination itself, or by the inclusion of patients receiving concurrently other drugs that might influence PRA. On the basis of some of these reports, it has been claimed that it may be dangerous to persist with long-term diuretic treatment if this leads to a persistent increase in PRA. This view is based on the contentious proposition that high PRA in a hypertensive population predisposes to vascular "events." $1:$ If such an association between PRA and vascular complications truly exists our results suggest that longterm diuretic treatment constitutes no threat by this mechanism.

We were pleased with the close correspondence of the conclusions drawn from this study conducted simultaneously in general practice and the hospital clinic. A collaborative study of this type has several obvious advantages. Firstly, patients are not divorced from their general practitioner during the clinical trial, and the general practitioner is intimately concerned both in recording and analysing the data. It would have been desirable to provide a more objective measurement of blood pressure using, for example, zero-muddled sphygmomanometers, but this would have been a costly modification of the protocol, which demanded measurements from 17 general practitioners. The incentive of being part of a collaborative study yields more suitable patients from general practice than might otherwise be the case and our experience is that the study has stimulated a continuing interest in the whole subject of detecting, investigating, and managing hypertension among the collaborative group.

Glaxo Laboratories provided financial support for this study. The manuscript was typed by Mrs E Grassam. Members of the Sheffield Collaborative Group in Hypertension participating in the study were: 
Drs H A Adam, M A Bacon, K C Baldwin, S L Barley, M Blindt, G Brennan, W G Cawtley, G E Clayton, V G S Damms, L Debson, A R Evans, C W Greaves, W E Greaves, M Hayes-Allen, B F Hallatt, B Hillman, J M Lloyd, T May, P G Norton, D Oates, I A J RossSmith, R Thompson, J D Warren, and S J Wright.

References

'Lambert, D M D, Practitioner, 1973, 210, 277.
2 General Practitioner Research Group, Practitioner, 1971, 206, 412.

${ }^{3}$ Cohen, E L, et al, fournal of Laboratory and Clinical Medicine, 1971, 77, 1025.

Boston Collaborative Drug Surveillance Program, Lancet, 1974, 2, 669.

Armstrong, B, et al, Lancet, 1974, 2, 672.

6 Heinonen, O P, et al, Lancet, 1974, 2, 675

Brunner, H R, et al, New England Fournal of Medicine, 1972, 286, 441

* Winer, N, et al, fournal of Clinical Endocrinology, 1969, 29, 1168.

${ }^{9}$ Muisan, G, et al, Clinical Science and Molecular Medicine, 1975, 48, 85s.

10 Tarazi, R C, et al, Circulation, 1970, 41, 709.

11 Bourgoignie, J J, et al, Circulation, 1968, 37, 27.

${ }^{12}$ Brunner, H R, et al, American fournal of Medicine, 1973, 55, 295.

\title{
Significance of variations in blood: breath partition coefficient of alcohol
}

\author{
T A A ALOBAIDI, D W HILL, J P PAYNE
}

British Medical fournal, 1976, 2, 1479-1481

\begin{abstract}
Summary
A helium-neon laser was used to measure the alcohol content of breath from six volunteers at regular intervals over up to four hours. The corresponding blood values were calculated with a blood:breath partition coefficient of 2100. When these values were compared with those obtained by direct measurement it was obvious that substantial variations occurred from one person to another in the derived values and that even in the same person the use of the partition coefficient of 2100 led to significant differences between the direct and derived values for blood, and these differences changed with time. Thus the assertion that a constant partition coefficient of 2100 exists between alcohol in blood and that in breath is not supported by the evidence. Accordingly the use of such a partition coefficient to derive blood alcohol values for law enforcement is not justified.
\end{abstract}

\section{Introduction}

The possibility that accurate blood alcohol values can be derived from measuring alcohol in breath has important implications in law, particularly in the United Kingdom in relation to the proposed revision of the relevant sections of the Road Traffic Act 1972. ${ }^{\circ}$ But before breath analysis can be accepted as a substantive test in the courts two vital questions need to be answered. Firstly, are techniques available that will allow the alcohol content of breath to be accurately determined ? Secondly, can an accurate determination of the alcohol content of blood be obtained from breath analysis by using of a universally applicable conversion factor? We describe here experiments carried out in an attempt to answer these questions.

Research Department of Anaesthetics, Royal College of Surgeons of England, London WC2A 3PN

T A A ALOBAIDI, PHD, MINSTP, research fellow (present address: Physiology Department, College of Medicine, Al-Mustansiriyah University, Baghdad, Iraq)

$D$ W HILL, PHD, FINSTP, reader in medical physics

J P PAYNE, MB, FFARCS, professor

\section{Method}

Breath was analysed with a helium-neon infrared analyser designed and built by Powell ${ }^{2}$ and modified specifically for measuring alcohol vapour in breath by Alobaidi. ${ }^{3}$ The apparatus has been described in detail elsewhere. ${ }^{4}$

Calibration ethanol-air mixtures were generated by a slow injector system" over the range of 5 to 28000 parts per million (ppm) by volume $(0.022-116 \cdot 3 \mu \mathrm{mol} / \mathrm{l}(1 \cdot 0-5356 \mu \mathrm{g} / \mathrm{l}))$ at $20^{\circ} \mathrm{C}$ and $760 \mathrm{~mm} \mathrm{Hg}$. Initially, the slow injector output was verified with the aid of a manometric mixing technique and a flame ionisation detector gas chromatograph with oxygen as an internal standard. ${ }^{3}$ These known ethanol-in-air concentrations were used to calibrate the analyser before and after analysing each batch of breath samples.

Six volunteers, five men and one woman aged 20 to 58 years and weighing 57 to $76 \mathrm{~kg}$ were studied. On arrival in the laboratory they had fasted and abstained from alcohol for at least 12 hours and had taken no soft drinks for at least four hours. Breath and venous blood samples were obtained as previously described. ${ }^{6}$ Five volunteers chose to drink whisky $70^{\circ}$ proof $100 \mathrm{ml}$ diluted with $100 \mathrm{ml}$ of water; the sixth preferred gin $70^{\circ}$ proof diluted with $100 \mathrm{ml}$ of tonic water. Up to three minutes was allowed for drinking, and in some cases this was followed by two minutes' mouthwashing. The length of each experiment varied but the average was three hours.

During the first two hours after drinking batches of three breath samples were taken in rapid succession at five- to 10 -minute intervals and then at 15-minute intervals. The mean value of the three results in each batch was calculated and recorded. Blood samples were withdrawn immediately after the third breath sample in each batch and stored in plastic pots $(0.3 \mathrm{ml})$ or glass phials $(1 \mathrm{ml})$. Only one type of container was used for each volunteer. The samples were stored in a domestic refrigerator until analysed by the method of Curry et al. ${ }^{\text {? }}$ All analyses were done in duplicate and many in triplicate.

The measured blood alcohol concentrations were compared with the calculated values derived from the measured breath concentrations. For this purpose the partition coefficient of $2100: 1$, recommended by the British Medical Association, ${ }^{8}$ was used. The actual partition coefficients were also calculated for each volunteer from paired breath and blood alcohol concentrations at regular intervals.

\section{Results}

\section{CALIBRATION STUDIES}

The results in table I indicate that a high degree of reproducibility was achieved at all three speeds over the range 205 to $1226 \mathrm{ppm}$. On the basis of calibration with such alcohol vapour mixtures the laser infrared analyser response was linear within $\pm 5 \%$ over the range $0-12000 \mathrm{ppm}$ of ethanol vapour by volume (0 to $49 \cdot 8 \mu \mathrm{mol} / 1(0-2296$ $\mathrm{\mu g} / \mathrm{l})$ at $20^{\circ} \mathrm{C}$ and $760 \mathrm{~mm} \mathrm{Hg}$ ). Over the range of interest of $0-500 \mathrm{ppm}$ (0 to $2.08 \mu \mathrm{mol} / \mathrm{l}(0-96 \mu \mathrm{g} / \mathrm{l})$ at $20^{\circ} \mathrm{C}$ and $760 \mathrm{~mm} \mathrm{Hg}$ ) ethanol vapour 